\title{
A study of cesarean section rate by using modified Robson's ten group classification system
}

\author{
Meha K. Patel*, Saloni M. Prajapati
}

Department of Obstetrics and Gynecology, GMERS Medical College, Gotri, Vadodara, Gujarat, India

Received: 20 May 2019

Accepted: 27 May 2019

*Correspondence:

Dr. Meha K. Patel,

E-mail: meha.pate1151@gmail.com

Copyright: (c) the author(s), publisher and licensee Medip Academy. This is an open-access article distributed under the terms of the Creative Commons Attribution Non-Commercial License, which permits unrestricted non-commercial use, distribution, and reproduction in any medium, provided the original work is properly cited.

\begin{abstract}
Background: High caesarean section rate worldwide including India is matter of concern. The Robson's Ten-group classification system allows critical analysis of caesarean deliveries according to characteristics of pregnancy. The objective was to analyze caesarean section rates in a tertiary care centre according to Modified Robson's ten groups classification.

Methods: This retrospective study was conducted at GMERS Gotri Medical College, Vadodara, Gujarat, India. All patients who delivered between August 2018 and March 2019, were included in the study. Women were classified in 10 groups according to modified Robson's classification using their maternal characteristics and obstetric history. For each group, authors calculated the caesarean section rate within the group and its absolute and relative contribution to the overall caesarean rate.

Results: Total number of delivery in my study institute in 8 months was 1531 out of them 456 was cesarean section, so the overall caesarean section rate was $29.78 \%$. The main contributions to overall caesarean rate was $40.78 \%$ by group 5 (previous CS, singleton, cephalic, $>37$ weeks) followed by $14.25 \%$ by group 1 (nullipara, singleton, cephalic, $>37$ weeks, spontaneous labour), $11.40 \%$ by group 2 (nullipara, singleton, cephalic,>37 weeks, induced or CS before labour). CS rates among various group ranges from $100 \%$ among women with abnormal lie (group 9) to $98.4 \%$ in previous CS (group 5), 84\% in nulliparous breech (group 6), 58\% in multiparous breech (group 7) and least $8.2 \%$ in multipara spontaneous labour (group 3).
\end{abstract}

Conclusions: The Robson's classification is easy to use. It is time to implement obstetric audit to lower the overall CS rates.

Keywords: Caesarean section rates, Clinical audit, Modified Robson's Ten-group classification system

\section{INTRODUCTION}

Ever since caesarean section has been introduced in obstetrical practice, it had revolutionized the modern obstetrical practice as many difficult instrumental delivery like mid-cavity forceps and abnormal vaginal delivery are obsolete now. But like any surgical interventions, it has its merits and demerits. For past few years there has been increased incidence of placenta praevia, placenta accrete syndrome, risk of rupture uterus in previous CS. High caesarean birth rates are an issue of international public health concern. ${ }^{1}$ In 1985, WHO (World Health Organisation) proposed the ideal rate of caesarean section between $10-15 \% .^{2}$ In India CS rate is increasing steadily and thus, need arises to focus on contributors and develop strategies to avoid unnecessary caesarean sections. There is need for an internationally accepted classification system for caesarean section that 
would allow meaningful and relevant comparison of CS rates.

Clinical audit is an important means to improve patient care through critical analysis and review of available data. The rising caesarean section (CS) rates have assumed epidemic proportion and need evidence-based strategies to safely reduce unnecessary CS in every institution. Dr Michael Robson, in 2001, proposed the need to adopt a standard classification system for easy comparison and bringing about evidence based improvement in obstetrics care. He introduced Robson classification, also called ten group classification system (TGCS), to standardise this clinical audit across different institutions. ${ }^{3,4}$ The size of the TGCS groups, and the CS rates in each group of this classification, contributes to the overall CS rate of the institution.

The World Health Organization (WHO) and the International Federation of Gynaecology and Obstetrics (FIGO) recommend the Robson TGCS as a standard for monitoring and comparing CS rates within heath care facilities. ${ }^{5,6}$

The characteristics used are:
- $\quad$ Single or multiple pregnancy

- Nulliparous, multiparous, or multiparous with a previous CS

- Cephalic, breech presentation or other malpresentation

- Spontaneous or induced labour

- Term or preterm births.

This classification has been widely used in various countries. It consists of 10 patient population categories that are mutually exclusive. A modification to the Robson criteria has been proposed by SOGC Committee (Society of Obstetricians and Gynecologist of Canada) which enable better comparison for CS rates. This modification includes sub classification of woman having caesarean section after spontaneous onset of labour, after induction of labour and before labour. ${ }^{7}$ Though there have been limitation to this modification also, still it is simple, easily implementable and a robust tool to monitor caesarean section rates (Table 1). The aim of this study was to initiate the collection of data and use of TGCS as a starting point to audit caesarean deliveries in present institution.

Table 1: Modified Robson's classification.

\begin{tabular}{|c|c|}
\hline Major group & Subgroup \\
\hline \multicolumn{2}{|l|}{ Nullipara, singleton cephalic, $\geq 37$ weeks, spontaneous labour } \\
\hline \multirow{2}{*}{ Nullipara, singleton cephalic, $\geq 37$ weeks } & Induced \\
\hline & Caesarean section before labour \\
\hline \multicolumn{2}{|l|}{ Multipara, singleton cephalic, $\geq 37$ weeks, spontaneous labour } \\
\hline \multirow{2}{*}{ Multipara, singleton cephalic, $\geq 37$ weeks } & Induced \\
\hline & Caesarean section before labour \\
\hline \multirow{3}{*}{ Previous caesarean section, singleton cephalic, $\geq 37$ weeks } & Spontaneous labour \\
\hline & Induced \\
\hline & Caesarean section before labour \\
\hline \multirow{3}{*}{ All nulliparous breeches } & Spontaneous labour \\
\hline & Induced \\
\hline & Caesarean section before labour \\
\hline \multirow{3}{*}{ All multiparous breeches (including previous caesarean section) } & Spontaneous labour \\
\hline & Induced \\
\hline & Caesarean section before labour \\
\hline \multirow{3}{*}{ All multiple pregnancies (including previous caesarean section) } & Spontaneous labour \\
\hline & Induced \\
\hline & Caesarean section before labour \\
\hline \multirow{3}{*}{ All abnormal lies(including previous caesarean section but excluding breech) } & Spontaneous labour \\
\hline & Induced \\
\hline & Caesarean section before labour \\
\hline \multirow{3}{*}{ All singleton cephalic, $\leq 36$ weeks (including previous caesarean section) } & Spontaneous labour \\
\hline & Induced \\
\hline & Caesarean section before labour \\
\hline
\end{tabular}

\section{METHODS}

This was a retrospective study conducted in the Department of Obstetrics and Gynaecolgy at GMERS medical college, Gotri, Vadodara, Gujarat, India, from August 2018 to March 2019. All women who delivered by CS during this period were included except women with gestational age less than 20 weeks and who 
delivered fetus less than 500 grams $\left(2^{\text {nd }}\right.$ trimester abortion were excluded). Relevant obstetric data was collected from labour room delivery register like gestational age, parity, number of fetuses, presentation of fetus, whether patient presented with spontaneous labour or was induced. Women were classified according to Modified Robson classification. For each group, authors calculated and analyzed the caesarean section rate within the group and its contribution to overall CS rate.

\section{Inclusion criteria}

- All women delivered by CS during the study period of eight months, from August 2018 to March 2019.

\section{Exclusion criteria}

- All normal deliveries

\section{Statistical analysis}

The demographic data and obstetric details, including pregnancy outcome were tabulated according to TGCS and analysed for this study. Descriptive statistical analysis was done, and percentages calculated.

\section{RESULTS}

A total 1531 patients delivered in our institute from August 2018 to March 2019. Out of 1531 women 456 underwent caesarean section, so caesarean rate in present study was $29.78 \%$ (Table 2). All women were grouped according to modified Robson's TGCS using maternal characteristics and obstetric history.

The whole sample was distributed into these mutually exclusive groups. For each group, authors calculated its relative size and its contribution to the overall caesarean rate. The characteristic of each group of Modified Robson's TGCS is presented in Table 1.

Table 2: Modified Robson ten group classification system (TGCS).

\begin{tabular}{|c|c|c|c|}
\hline Group & Description & Data & Total \\
\hline 1 & Nullipara, single, cephalic, equal to or $>37$ weeks-spontaneous labour & 65 & 315 \\
\hline \multirow{3}{*}{2} & Nullipara, single, cephalic, equal to or $>37$ weeks & & \\
\hline & A: Induced & 39 & 119 \\
\hline & B: CS before labour & 13 & 13 \\
\hline 3 & Multipara, single, cephalic, equal to or $>37$ weeks-spontaneous labour & 42 & 511 \\
\hline \multirow{3}{*}{4} & Multipara, single, cephalic, equal to or $>37$ weeks & & \\
\hline & A: Induced & 14 & 88 \\
\hline & B: CS before labour & 01 & 04 \\
\hline \multirow{4}{*}{5} & Previous CS, single, cephalic, $>37$ weeks & & \\
\hline & A: Spontaneous labour & 63 & 66 \\
\hline & B: Induced & 0 & 0 \\
\hline & C: CS before labour & 123 & 123 \\
\hline \multirow{4}{*}{6} & All Nulliparous Breech & & \\
\hline & A: Spontaneous labour (4) & 04 & 08 \\
\hline & B: Induced & 00 & 00 \\
\hline & C: CS before labour & 17 & 17 \\
\hline \multirow{4}{*}{7} & All Multipara Breech (including previous CS) & & \\
\hline & A: Spontaneous labour & 08 & 22 \\
\hline & B: Induced & 00 & 00 \\
\hline & C: CS before labour & 12 & 12 \\
\hline \multirow{4}{*}{8} & All Multiple pregnancy (including previous CS) & & \\
\hline & A: Spontaneous labour & 01 & 09 \\
\hline & B: induced & 00 & 00 \\
\hline & C: CS before labour & 00 & 00 \\
\hline \multirow{4}{*}{9} & All abnormal Lies (including previous CS) & & \\
\hline & A: Spontaneous labour & 01 & 01 \\
\hline & B: Induced & 00 & 00 \\
\hline & C: CS before labour & 08 & 08 \\
\hline \multirow{4}{*}{10} & All single, cephalic, $<37$ Weeks (including previous CS) & & \\
\hline & A: Spontaneous labour & 22 & 177 \\
\hline & B: Induced & 10 & 25 \\
\hline & C: CS before labour & 13 & 13 \\
\hline Total & & 456 & 1531 \\
\hline
\end{tabular}


Maximum number of women of $511(33.34 \%)$ were in group 3 followed by $315(20.57 \%)$ women in group 1 , then group 10 consist of $215(14.04 \%)$, then group 5 consist of $189(12.34 \%)$ women whereas $132(08.62 \%)$ women in group 2. Less number of women $92(06.01 \%)$ in group $4,34(02.22 \%)$ in group $7,25(01.63 \%)$ women in group 6, $9(00.59 \%)$ women in group 8 and group 9 each (Table 2). In group 1, 65 out of 315 were CS, 52 out of 132 were CS in group 2, 42 out of 511 in group 3, 15 out of 92 in group 4, 186 out of 189 in group 5, 21 out of 25 in group 6, 20 out of 34 in group 7, 1 out of 9 in group 8,9 out 9 in group 9 and 45 out of 215 were CS in group 10 (Table 2).

Caesarean section rate within the group was maximum in group $9(100 \%)$, then $98.4 \%$ in group $5,84 \%$ in group 6 , $58.82 \%$ in group $7,39.39 \%$ in group $2,20.93 \%$ in group $10,20.63 \%$ in group 1 . Less CS rate within the group were in group $4(16.30 \%)$, group $8(11.11 \%)$ and least rate was in group $3(08.21 \%)$ (Table 3$)$.

The maximum contribution to total $\mathrm{CS}$ is from group 5 (40.78\%), followed by group 1 (14.25\%), group 2
(11.40\%), group $10(9.86 \%)$ and group $3(9.21 \%)$. Less contribution from group $6(4.60 \%)$, group $7(4.38 \%)$, group $4(3.28 \%)$, group $9(1.97 \%)$ and least from group 8 $(0.21 \%)$ (Table 4$)$.

Table 3: Caesarean rate within the group.

\begin{tabular}{|llll|}
\hline Group & No. of CS & $\begin{array}{l}\text { No. of total } \\
\text { deliveries }\end{array}$ & $\begin{array}{l}\text { Group CS } \\
\text { rate }(\%)\end{array}$ \\
\hline 1 & 65 & 315 & 20.63 \\
\hline 2 & 52 & 132 & 39.39 \\
\hline 3 & 42 & 511 & 08.21 \\
\hline 4 & 15 & 92 & 16.30 \\
\hline 5 & 186 & 189 & 98.41 \\
\hline 6 & 21 & 25 & 84 \\
\hline 7 & 20 & 34 & 58.82 \\
\hline 8 & 01 & 09 & 11.11 \\
\hline 9 & 09 & 09 & 100 \\
\hline 10 & 45 & 215 & 20.93 \\
\hline Total & $\mathbf{4 5 6}$ & $\mathbf{1 5 3 1}$ & $\mathbf{2 9 . 7 8}$ \\
\hline
\end{tabular}

Table 4: Absolute and relative group contribution of CS in overall CS rate.

\begin{tabular}{|llll|}
\hline Group & No. of CS & $\begin{array}{l}\text { Absolute group contribution to overall CS } \\
\text { rate }(\%)\end{array}$ & $\begin{array}{l}\text { Relative group contribution to overall CS } \\
\text { rate }(\%)\end{array}$ \\
\hline 1 & 65 & 14.25 & 04.24 \\
\hline 2 & 52 & 11.40 & 03.39 \\
\hline 3 & 42 & 09.21 & 02.74 \\
\hline 5 & 15 & 03.28 & 00.97 \\
\hline 6 & 186 & 40.78 & 12.14 \\
\hline 7 & 21 & 04.60 & 01.37 \\
\hline 8 & 01 & 04.38 & 01.30 \\
\hline 9 & 09 & 01.97 & 00.06 \\
\hline 10 & 45 & 09.86 & 00.58 \\
\hline
\end{tabular}

\section{DISCUSSION}

When medically justified, a CS can effectively prevent maternal and perinatal mortality and morbidity. CS is the recommended mode of delivery in transverse lie or nullipara with breech presentation, and it is considered appropriate and justified for this category of women. However, in women where CS is done purely on maternal request, without a medical indication, CS cannot be considered as appropriate or justified. When CS is done for foetal distress, sometimes on delivery the foetus is depressed and has to be admitted to neonatal intensive care unit (NICU) for its survival, whereas, at other times the foetus is born healthy and with good Apgar scores. Hence, CS for this category of women is always a dilemma for the obstetrician. Women with previous scarred uterus make up another debatable category for
CS. All categories of women contribute to the overall CS rate of the institution. Hence, it has been suggested that the overall institutional CS rate should no longer be thought of as being too high or too low, but rather, whether they are appropriate or not.

This study was an attempt to use modified Robson TGCS to audit caesarian sections in present institution, and to understand the reasons behind the CS rates for different groups of TGCS specific to present institution.

The overall CS rate of present institution for the eightmonth study period was $29.78 \%$ i.e. 456 CS of 1531 total deliveries. Sneha et al, also reported a similar CS rate of $32.6 \%$ at a tertiary care teaching hospital in South India. ${ }^{8}$ Arpita et al, also reported a high overall CS rate of 
$44.61 \%$ from another large teaching hospital in Karnataka. $^{9}$

The first group of TGCS is traditionally a large group, and therefore, accounts for a sizable percentage of the overall CS rate. $14.25 \%$ of CS was done in nulliparous women in spontaneous labor at term, indicating that authors are dealing with a relatively high-risk population in group 1 of TGCS. Almost half of these women underwent CS for fetal distress; other common indications for referral to present institution were arrest of dilatation and non-progress of labor.

Women in group 2A where labor was induced, constituted $8.55 \%$ of overall CS rate in present institution. Indications for induction of labor were varied. However, within this group the commonest indication for induction was "postdates", i.e. beyond the expected date of delivery. NICE guidelines recommend that these women should be offered induction of labor between 41 and 42 weeks, to avoid the risks of prolonged pregnancy. Maternal anxiety and family pressure to hasten the delivery process, as well as, obstetricians desire to avoid sudden fetal demise often contribute to induction before 42 weeks of gestation.

Some systematic reviews state that the risk of CS is not increased due to induction of labor, however, the procedure itself is not without risk. Recently, Mahomed et al reported from a retrospective cohort study, involving only nulliparous women with uncomplicated singleton pregnancy at 40-0 to 41-6 weeks, that incidence of CS was significantly higher in the induction group at 40-0 to 41-6 weeks when compared to women with spontaneous labor at 40-0 to 41-6 weeks. ${ }^{10}$ Counseling by senior obstetrician and adhering to guidelines may see more women progress to spontaneous labor and thus avoid unnecessary inductions and CS in this group of TGCS.

Group 2B were primipara who underwent CS before the onset of labor and contributed to $2.85 \%$ of present overall CS rate. Jogiya $\mathrm{P}$ et al found similar CS rate from group 2B (2.46\%). ${ }^{11}$ Tanaka et al, from Australia, found that this group contributed only $0.5 \%$ to their overall CS rate. $^{12}$

Group 3 contributed to $9.21 \%$ of present overall CS rate. This rate is similar to study by Priyanka et al $(16.31 \%) .{ }^{11}$

Group 4 constituted $3.28 \%$ of present overall CS rate. The common indications were "postdates", prelabour rupture of membranes and hypertensive disorders. Other study has stated similar contribution from this group, $2.3 \%$ to their overall CS rate. ${ }^{12}$

Group 5 with previous CS pregnancy at term, was the largest contributor with $40.78 \%$ of the overall CS rate mostly due to women having CS prior to labour (group 5C). Group 5C made up 66\% of group 5. $15.3 \%$ of this group had previous two or more CS. Only 3 women had
VBAC during the study period and they were admitted to labour room in an active stage of labour. $98.4 \%$ of women of group 5 were delivered by CS. This finding is in agreement with studies done by Kansara Vijay et al (98.3\%). ${ }^{13}$ There was $36.96 \%$ of overall CS rate of group 5 in the study done by Jogiya $\mathrm{P}$ et al. ${ }^{11}$ Comparable CS rate $(40.1 \%)$ found in study done by Dhodapkar SB et al. ${ }^{8}$ Even though vaginal birth after one CS has been advocated as a safe option, the number of women who attempt trial of labour after caesarean has declined over recent years due to fear of uterine rupture, as well as, the fear of litigations, amongst the care givers, in case anything goes wrong. ${ }^{14-18}$ Increasing CS rate among women with breech presentation is a common phenomenon particularly since the publication of the term breech trial, and present hospital is no exception. ${ }^{19,20}$ Groups 6 and 7 consist of women with breech presentation and show a high CS rates. Group 6 contributes to $4.6 \%$ of overall CS rate. $84 \%$ women of group 6 delivered by CS. 4 women delivered vaginally in group 6. Group 7 contributes to $4.38 \%$ of overall CS rate. $58.8 \%$ women of group 7 delivered by CS. These findings are similar to $91.3 \%$ (group 6) and $77.7 \%$ (group 7) of the study done by Tanaka et al and Panicker $S$ et al respectively. ${ }^{12,21}$ Even though this group is relatively small, authors should be more proactive in offering external cephalic version to all eligible women with breech presentation and consider offering vaginal breech delivery to suitable women.

Group 8 had only 1 CS $(0.21 \%$ of overall CS rate) for twin gestations. There were eight vaginal twin deliveries during the study period $(11.11 \%)$. It is similar to study by Jacob KJ et al $(21.6 \%)$. ${ }^{22}$ There were 9 CS $(1.97 \%$ of overall CS rate) for malpresentations in group 9. All 9 women were delivered by CS $(100 \%)$. It is similar to study by Tanaka et al $(100 \%){ }^{12}$

Group 10, women birthing before 37 weeks, contributed to $9.86 \%$ of overall CS rate. Preterm labor, hypertensive disorders and gestational diabetes mellitus were the main contributors to this group. Group 10 contributed $7.4 \%$ and $9.7 \%$ to the overall institutional CS rates in different studies from India. ${ }^{23,8}$

The proportion of women who had previously had a caesarean section increased in most countries across the world. It would be prudent to explore measures to decrease primary CS for women in groups 1, 2, 3 and 4. This will, in time, affect the overall CS rates in group 5. Where facilities exist, trial of labor after cesarean (TOLAC) should be offered to women with previous CS after proper patient selection and counseling. This is the only way to reduce CS rates in group 5.

Robson TGCS is simple and reproducible classification, but also has certain limitations. It does not take into account the indications for induction of labor or CS, e.g. abruptio placenta or preterm eclampsia, where CS is considered a lifesaving procedure. It also does not 
account for pre-existing medical, surgical or foetal disease and the degree of prematurity; all of which may influence the decision to undertake CS. No information regarding women who have undergone trial of labor after CS (TOLAC) is obtained from TGCS. Many modifications to TGCS have been proposed to overcome these deficiencies, but none has gained universal acceptance nor stood the test of time. ${ }^{24,25}$

\section{CONCLUSION}

The use of Robson TGCS is recommended for medical audit in all maternity suits. Authors have used TGCS as the starting point for baseline data for audit in present institution, and authors intend to repeat the process over time to monitor the change in CS rates and improve quality of patient care.

\section{ACKNOWLEDGMENTS}

Authors would like to thank HOD and professors of Department of Obstetrics and Gynaecology, GMERS medical college, Gotri, Vadodara, Gujarat, India, for their wholehearted guidance and support during the study.

Funding: No funding sources

Conflict of interest: None declared

Ethical approval: Not required

\section{REFERENCES}

1. Romero Von Roosenmalen J, Van der Does CD. Caesarean birth rate worldwide. A search for determinants. Trop Geogr Med.1995;47(1):19-22.

2. World Health Organization. Appropriate technology for birth. Lancet. 1985;326(8452):436-7.

3. Torloni MR, Betran AP, Souza JP, Widmer M, Allen T, Gulmezoglu M, et al. Classifications for cesarean section: a systematic review. PLoS One. 2011;6(1):e14566.

4. Betran AP, Vindevoghel N, Souza JP, Gülmezoglu AM, Torloni MR. A systematic review of the Robson classification for caesarean section: what works, doesn't work and how to improve it. PLoS One. 2014;9(6):e97769.

5. World Health Organization. WHO Statement on Caesarean Section Rates. WHO/RHR/15.02; 2015.

6. FIGO working group on challenges in care of mothers and infants during labour and delivery. Best practice advice on the 10-group classification system for cesarean deliveries. Int $\mathbf{J}$ Gynaecol Obstet. 2016;135:232-3.

7. SOGC Committee Opinion. Classification of Caesarean section in Canada: The Modified Robson Criteria. J Obstet Gynaecol Can. 2012;34(10):976-9.

8. Dhodapkar S, Sindhu B, Daniel M, Chauhan N, Chauhan R. Analysis of caesarean sections according to Robson's ten group classification system at a tertiary care teaching hospital in South India. Int J Reproduct Contra Obstet Gynecol. 2015:745-749.
9. Reddy AY, Dalal A, Khursheed R. Robson ten group classification system for analysis of cesarean sections in an Indian hospital. Res J Obstet Gynecol. 2018;11:1-8.

10. Mahomed K, Pungsornruk K, Gibbons K. Induction of labour for postdates in nulliparous women with uncomplicated pregnancy-is the caesarean section rate really lower? J Obstet Gynaecol. 2016;36(7):916-20.

11. Jogia D, Lodhiya P, Kaushik. Analysis of caesarean sections according to modified Robson's ten group classification system at a tertiary care centre in Western India. Int J Repro Contra Obstet Gynecol. 2019;8.

12. Tanaka K, Mahomed K. The ten-group Robson classification: A single centre approach identifying strategies to optimise caesarean section rates. Obstet Gynecol Int. 2017;2017.

13. Kansara V, Patel S, Aanand N, Muchhadia J, Kagathra B, Patel R. A recent way of evaluation of cesarean birth rate by Robson's 10-group system. J Med Pharmaceut Allied Sci. 2014;01:62-70.

14. Royal College of Obstetricians and Gynaecologists, birth after previous caesarean birth (Green Top Guideline 45), RCOG, London, UK, 2015.

15. The Society of Obstetricians and Gynaecologists of Canada (SOGC), "Guidelines for vaginal birth after previous caesarean birth," 2005. Available at; http://sogc.org/wp- content/uploads/2013/01 /155ECPG- February2005.pdf.

16. The American College of Obstetricians and Gynecologists (ACOG), "Vaginal birth after previous cesarean delivery," 2010. Available at; http://www.acog.org/Resources-And- Publications/ Practice-Bulletins/Committee-on-Practice-BulletinsObstetrics/Vaginal-Birth-After-Previous-CesareanDelivery.

17. Grobman WA, Lai Y, Landon MB, Spong CY, Rouse DJ, Varner MW, et al. The change in the VBAC rate: an epidemiologic analysis. Paediatr Perinatal Epidemiol. 2011;25(1):37.

18. Yeh J, Wactawski-Wende J, Shelton JA, Reschke J. Temporal trends in the rates of trial of labor in lowrisk pregnancies and their impact on the rates and success of vaginal birth after cesarean delivery. Am J Obstet Gynecol. 2006;194(1):144-e1.

19. Hannah ME, Hannah WJ, Hewson SA, Hodnett ED, Saigal S, Willan AR, et al. Planned caesarean section versus planned vaginal birth for breech presentation at term: a randomised multicentre trial. Lancet. 2000;356(9239):1375-83.

20. Hehir MP. Trends in vaginal breech delivery. J Epidemiol Community Health. 2015;69(12):1237-9.

21. Panicker S, Chitra TV. Analysis of caesarean delivery rates using the ten group classification system in a tertiary care hospital. Int $\mathrm{J}$ Reprod Contracept Obstet Gynecol. 2016;5(9):3153-7.

22. Jacob KJ, Megha J, Hibina KP. TMC (Thrissur Medical College) modified Robson criteria for 
caesarean sections. Int J Reprod Contracept Obstet Gynecol. 2017;6(11):5038-43.

23. Kant A, Mendiratta S. Classification of cesarean section through Robson criteria: an emerging concept to audit the increasing cesarean section rate. Int $\mathrm{J}$ Reprod Contracept Obstet Gynecol. 2018;7:4674-7.

24. Farine D, Shepherd D. Classification of caesarean sections in Canada: the modified Robson criteria. J Obstet Gynecol Canada. 2012;34(10):976-9.

25. Prameela RC, Farha A, Bhanumathi PM, Prajwal S. Analysis of caesarean section rate in a tertiary hospital according to Robson's ten group classification system. IOSR J Dent Med Sci. 2015;14(2):46-9.

Cite this article as: Patel MK, Prajapati SM. A study of cesarean section rate by using modified Robson's ten group classification system. Int J Reprod

Contracept Obstet Gynecol 2019;8:2610-6. 